\title{
Circuit Breaker Failure Protection Strategy for HVDC Grids
}

\author{
María José Pérez-Molina *(D), Dunixe Marene Larruskain, Pablo Eguia (D) and Oihane Abarrategi \\ Department of Electrical Engineering, University of the Basque Country UPV/EHU, Plaza Ingeniero Torres \\ Quevedo, 1, 48013 Bilbao, Spain; marene.larruskain@ehu.eus (D.M.L.); pablo.eguia@ehu.eus (P.E.); \\ oihane.abarrategui@ehu.eus (O.A.) \\ * Correspondence: mariajose.perez@ehu.eus
}

check for

updates

Citation: Pérez-Molina, M.J.

Larruskain, D.M.; Eguia, P.;

Abarrategi, O. Circuit Breaker Failure Protection Strategy for HVDC Grids.

Energies 2021, 14, 4326. https:/ /

doi.org/10.3390/en14144326

Academic Editor: Athula

D. Rajapakse

Received: 23 June 2021

Accepted: 16 July 2021

Published: 18 July 2021

Publisher's Note: MDPI stays neutral with regard to jurisdictional claims in published maps and institutional affiliations.

Copyright: (c) 2021 by the authors. Licensee MDPI, Basel, Switzerland. This article is an open access article distributed under the terms and conditions of the Creative Commons Attribution (CC BY) license (https:/ / creativecommons.org/licenses/by/ $4.0 /)$.
Abstract: HVDC grids demand the fast and reliable operation of the protection system. The failure of any protection element should initialize a backup protection almost immediately in order to assure the system's stability. This paper proposes a novel backup strategy that covers the failure of the primary protection including the malfunctioning of the HVDC circuit breaker. Only local voltage measurements are employed in the proposed backup protection and the voltage derivative is calculated at both sides of the limiting inductor. Consequently, the speed and reliability of the protection system are enhanced, since no communication channel is needed. This paper contains a thorough specification of the proposed protection strategy. This strategy is validated in a fourterminal HVDC grid with various fault case scenarios, including high-resistance fault cases. The operation of the backup protection is reliable and remarkably fast.

Keywords: algorithm; circuit breaker failure; HVDC grid; protection

\section{Introduction}

The protection system of HVDC grids must operate in a few milliseconds in order to assure the system's stability. In consequence, in such a short time span faults must be detected and located by protection relays and finally cleared by the switching devices. The feasibility of HVDC grids demands fault isolation in all transmission links before it impacts the DC voltage of the unaffected parts of the grid [1]. Therefore, the location of HVDC circuit breakers (CBs) at both ends of the links is essentially forced.

A backup protection system is required in the case of failure or inability of the main protection relays or switching devices. Due to the HVDC grid requirements, backup protection must operate as fast as possible [2].

The huge requirements for HVDC CBs include a remarkably short operation time for interrupting large fault currents without any natural zero crossing as well as dissipating large amounts of energy stored in the inductances of the system $[3,4]$.

There has been a large development of HVDC CBs over last few years and, as a consequence, nowadays CBs are feasible, although still not commercially available [5]. The limited HVDC CBs, which are currently in service, have been manufactured as vendor solutions [6]. Due to the lack of operational experience, the test requirements are not clearly defined and in addition there is little information regarding the performance of those switching devices [7].

In consequence, procedures for the secure and rapid detection of the $\mathrm{CB}$ failure are required. Nevertheless, reliable and robust relaying mechanisms are demanded in the case of CB maloperation [8]. There are several proposals for covering the failure of CBs.

In [9], a CB failure backup protection algorithm is proposed. The CB failure is detected by means of voltage-current loci, resulting in a fast backup protection that is applied in a symmetrical monopolar system. The authors enhance the algorithm to bipolar systems and evaluate the robustness of the backup protection in [10].

Reference [11] proposes two backup algorithms to detect local and remote CB malfunction. The proposed algorithms detect the CB failure based on thresholds of the voltage and 
current measurements. The backup protection is assessed in a four-terminal HVDC grid with different location fault case scenarios; however, it does not consider the fault resistance.

The authors of [12] consider breaker and relay failure subsystems and classify the failure of the primary protection in the function of the voltage and current of the CB. The failures are classified according to a KNN nearest neighbor classifier and different actions are taken according to the class type. The algorithm presents a brief delay between the operation of primary and backup protections. Nevertheless, the algorithm is once more exclusively validated with solid faults.

This paper proposes a novel protection strategy that minimizes the consequences of $\mathrm{CB}$ failure in order to enhance the performance in addition to the availability of the protection system. This strategy is based on a new backup algorithm that considers the malfunctioning of CBs with only local measurements. Local strategies are widely accepted for meeting the demanding protection requirements [13,14].

The algorithm is based on the voltage derivative, which provides the required fast and reliable protection. The operating principle of the proposed strategy is discussed and applied in a four-terminal HVDC grid. Different fault case scenarios are analyzed including high-resistance faults, which can be challenging for derivative algorithms. Besides, high-resistance faults have not been previously considered in the literature to the best of the authors' knowledge. Finally, the operation of primary and backup protections is discussed; in this way, both protections are compared, taking into account operation time and interrupted current.

\section{Proposed Backup Protection}

The reliability of the HVDC grid must be ensured even if the failure of a circuit breaker happens. Then, a backup protection must be applied in order to detect the circuit breaker's failure. Meanwhile, conventional backup protections detect the failure of the circuit breaker after the estimated fault clearing time. However, the restrictive speed requirement related to HVDC grids entails the implementation of a fast backup protection capable of detecting and interrupting the fault current before it overcomes the current constraints of the circuit breakers and the Voltage Sourced Converters (VSC) [15]. In this regard, this work presents a backup protection based on local voltage measurements that is capable of quickly detecting the circuit breaker's failure before the estimated fault clearing time has passed. This way, the system has to interrupt a lower fault current than if the backup protection waits until the estimated fault clearing time passes.

The proposed protection system exploits the characteristic damping effect of the limiting inductors, which delimit the protection zones. This way, voltage measurements are taken at both sides, as is shown in Figure 1. The voltage measurements taken at the line side of the inductor, $\mathrm{V}_{\mathrm{L}}$, are used for the primary protection algorithm, while those taken at the bus side, $\mathrm{V}_{\mathrm{B}}$, are employed for the backup protection algorithm.

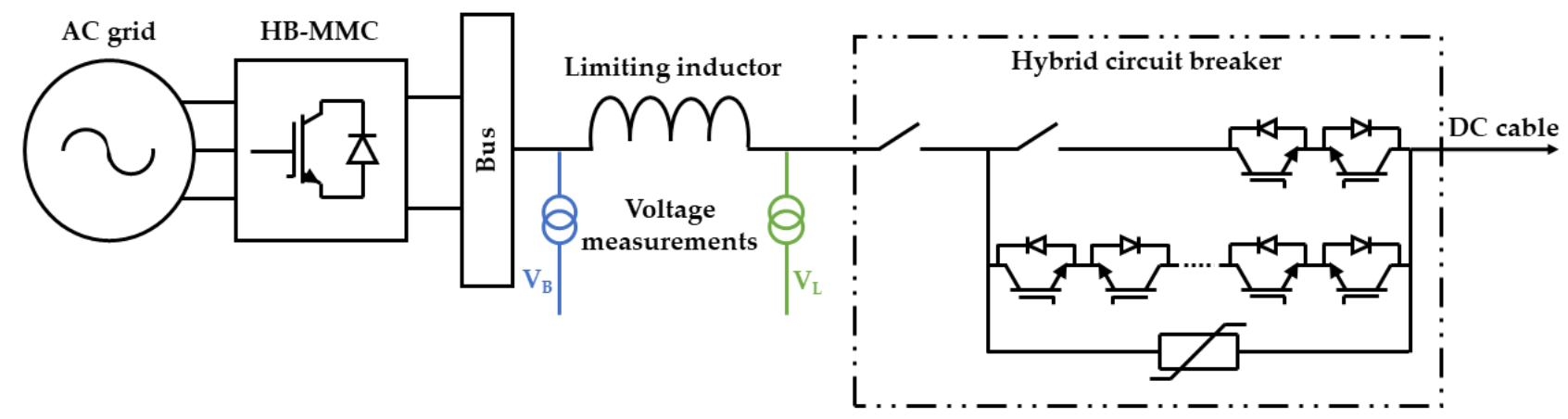

Figure 1. Diagram of the voltage measurements at both sides of the limiting inductor.

These measurements are processed and their derivatives are calculated. Therefore, both primary and backup protections are based on the Rate-Of-Change-Of-Voltage (RO- 
$\mathrm{COV}$ ) algorithm. This fault detection method presents a very fast operation due to faultinduced collapse of the DC voltage, which can be seen in Figure 2a,c. During normal conditions, the ROCOV value is close to zero while a sharp negative change is detected after fault inception, as is shown in Figure 3.

This method is widely found in the literature since it presents higher sensitivity to high-resistance faults and faster fault detection than current-based algorithms, e.g., [16-22]. Consequently, it has been selected for its application in this work as both primary and backup protections due to the restrictive speed requirement related to VSC-based systems, i.e., the fast rate of rise of the fault current and the low overcurrent withstand capability of the VSC's components.

Therefore, the primary and backup protections employ $V_{L}$ and $V_{B}$ measurements, respectively, calculate their derivatives and then compare them with their respective threshold values $T H R_{L}$ and $T H R_{B}$. The primary protection aims to detect all faults happening inside its protection zone, which, in this paper, refers to the cable where the relay is placed. This way, after fault inception $\left(t_{f}\right)$, the calculated $\operatorname{ROCOV}_{\mathrm{L}}$ falls under the pre-selected threshold value $\mathrm{THR}_{\mathrm{L}}$, as shown in Equation (1).

$$
\operatorname{ROCOV}_{\mathrm{L}}=\frac{\mathrm{V}_{\mathrm{L}_{2}}-\mathrm{V}_{\mathrm{L}_{1}}}{\mathrm{t}_{2}-\mathrm{t}_{1}}<\mathrm{THR}_{\mathrm{L}}
$$

Figures 2 and 3 present different waveforms regarding the voltage and ROCOV values when different fault conditions happen at time $120 \mathrm{~ms}$. Normal operation as well as the worst fault cases scenarios are presented, i.e., a close-up external fault that can be misdetected as an internal fault and a far-end internal fault that may not be detected if the primary algorithm is not sensitive enough. As it can be seen, during normal operation and close-up external fault conditions the ROCOV value is zero or a very low value in comparison with those measured when an internal fault happens. A threshold value is selected in order to discriminate between internal faults and external or normal operation conditions.

By that moment, fault detection by the primary protection algorithm is achieved $\left(t_{d P}\right)$ and a tripping signal is sent to the corresponding circuit breaker. It operates $\left(t_{\mathrm{oP}}\right)$ and the fault is cleared $\left(t_{\mathrm{CP}}\right)$. The primary protection's time steps are depicted in Figure 4 , as well as those corresponding to the backup protection that is explained hereunder.

On the other hand, the objective of the backup protection is to detect the failure to trip of a neighboring circuit breaker. Thus, the backup protection operates when fault detection is achieved on an adjacent link but the corresponding circuit breaker does not operate correctly due to a failure. All neighboring relays must detect the affected circuit breaker's failure and trip their corresponding circuit breakers in order to properly clear the fault.

As previously mentioned, the requirement of operation speed is critical in VSC-based systems, as an excessive delay in tripping enlarges the consequences of the failure. Consequently, only local measurements are employed in order to make the backup protection as fast as possible and the ROCOV algorithm is selected since it presents one of the fastest fault detection capabilities among the local-measurement-based methods commonly employed in HVDC systems. However, the proposed backup protection scheme could be applied and adjusted to other primary algorithms as long as they are fast enough to detect DC faults while satisfying the restrictive speed requirement. The backup process is initiated $\left(t_{i B U}\right)$ when a fault is detected on an adjacent link and the calculated $\mathrm{ROCOV}_{\mathrm{B}}$ obtains a value lower than the threshold value $\mathrm{THR}_{\mathrm{B}}$, as shown in Equation (2).

$$
\operatorname{ROCOV}_{\mathrm{B}}=\frac{\mathrm{V}_{\mathrm{B}_{2}}-\mathrm{V}_{\mathrm{B}_{1}}}{\mathrm{t}_{2}-\mathrm{t}_{1}}<\mathrm{THR}_{\mathrm{B}}
$$

Afterwards, the backup process is kept in standby for a time ( $\left.\mathrm{t}_{\mathrm{BUdelay}}\right)$ slightly greater than the operation time of the circuit breaker $\left(t_{C B}\right)$ so that the appropriate operation of the primary protection can be ensured before the backup protection's operation. 


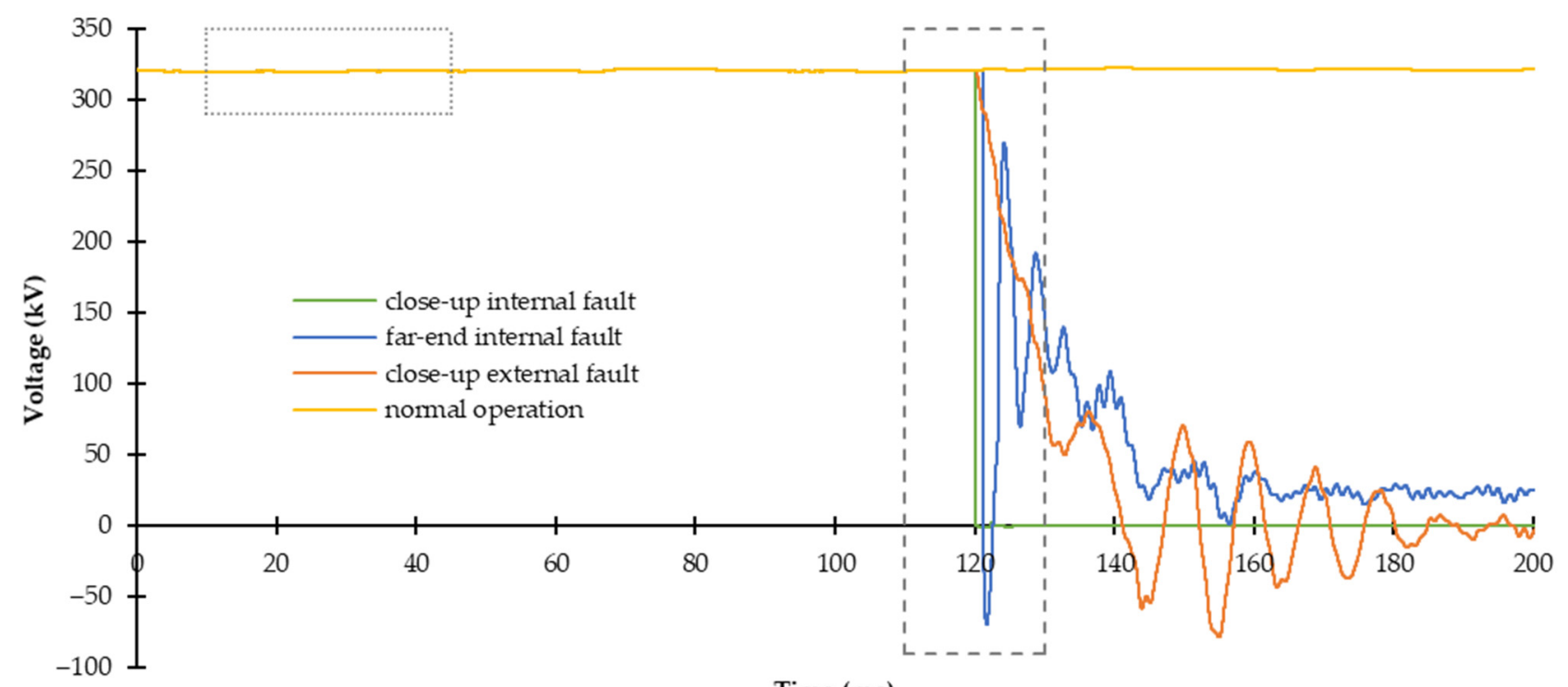

Time (ms)

(a)

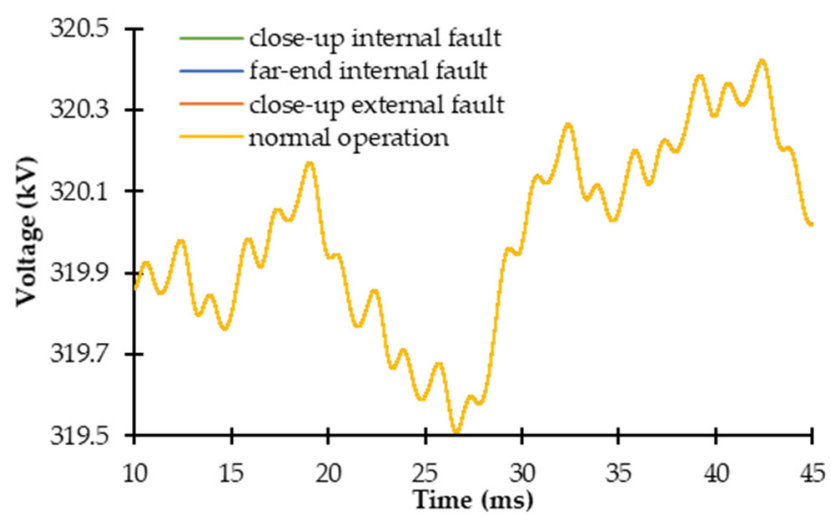

(b)

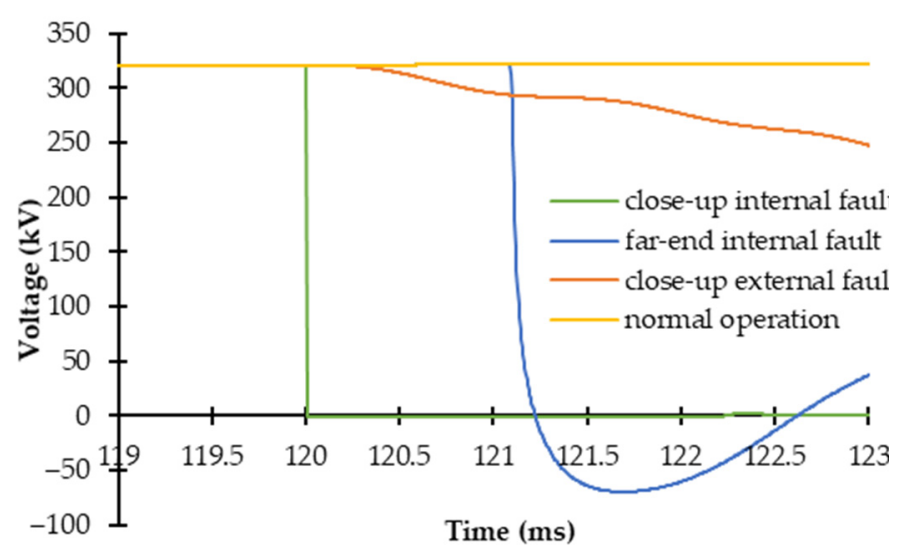

(c)

Figure 2. (a) Fault-induced DC voltage for different fault conditions, (b) voltage in steady-state, zoom in dotted square between 10 and $45 \mathrm{~ms}$, and (c) voltage under fault conditions, zoom in dashed line square between 199 and 123 ms.

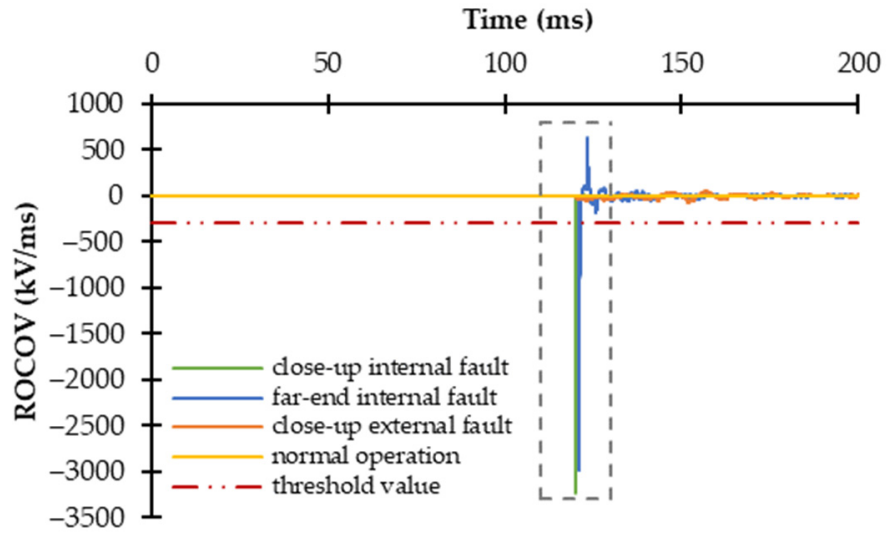

(a)

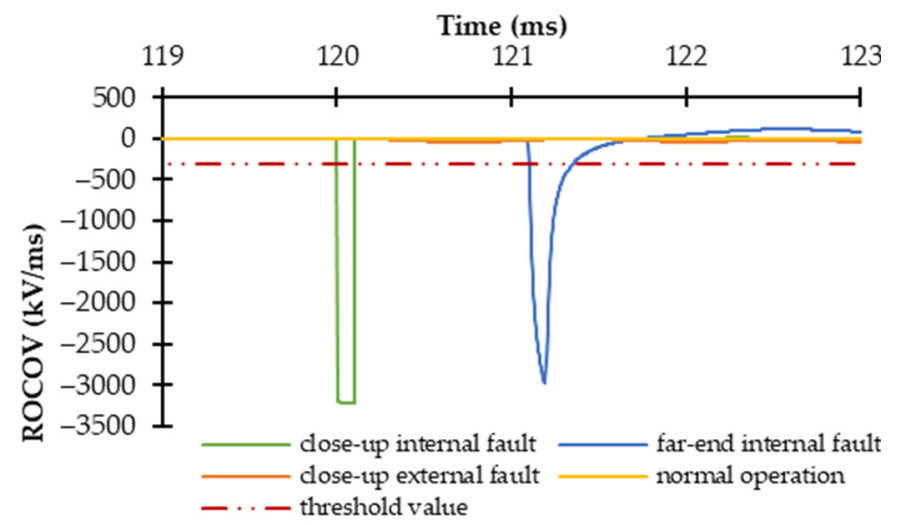

(b)

Figure 3. (a) ROCOV values for different fault conditions and (b) zoom in dashed line square between 199 and $123 \mathrm{~ms}$. 


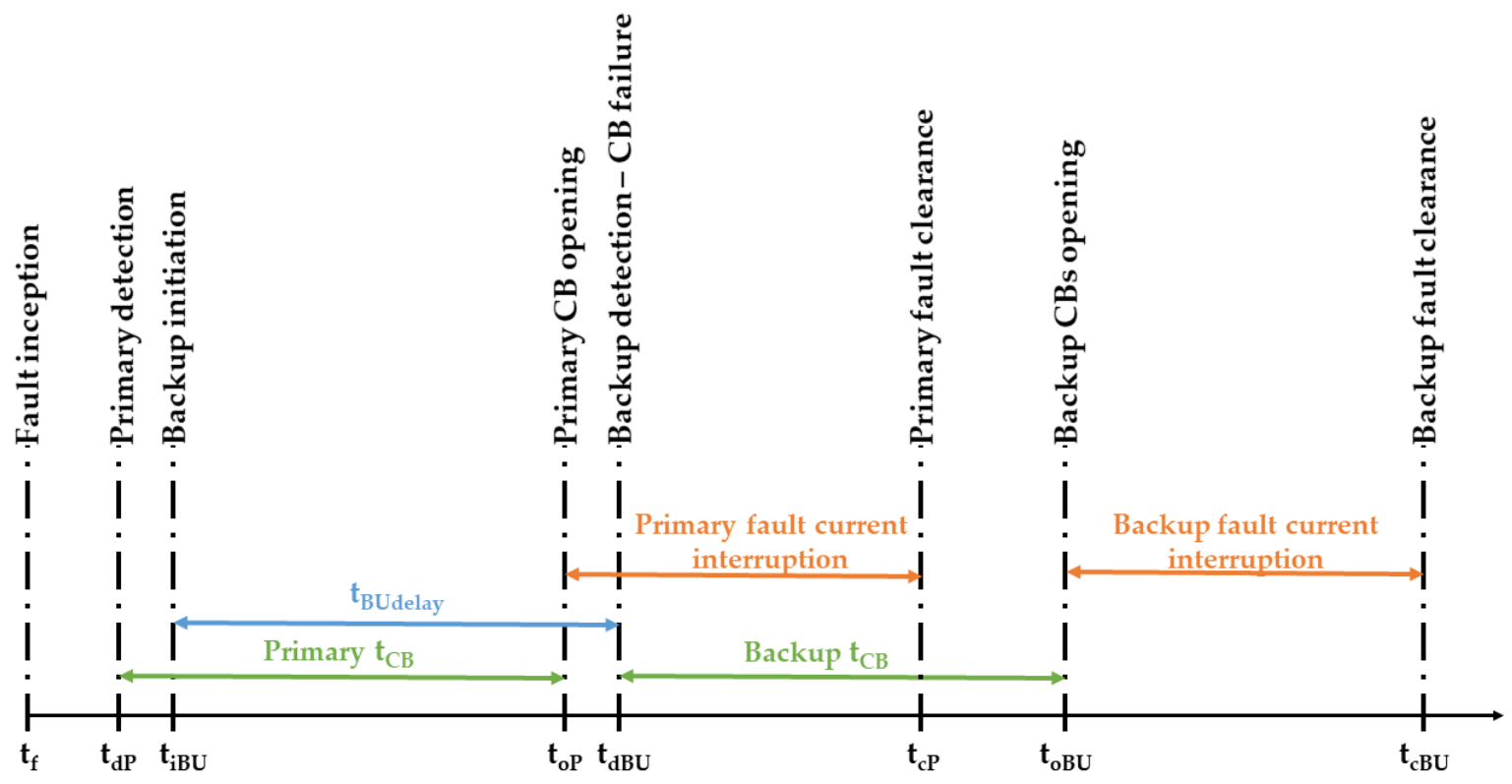

Figure 4. Time diagram of the proposed backup protection.

Therefore, the presented work assumes that a failure has happened when the current has not been commutated to the energy absorbing branch of the circuit breaker after $t_{c b}[11]$. After this time, the correct operation of the affected circuit breaker is checked. If it has operated, the backup process is terminated and the fault is cleared by the affected circuit breaker $\left(t_{c P}\right)$. Otherwise, a circuit breaker failure is detected $\left(t_{d B U}\right)$ and in consequence the corresponding neighboring circuit breakers operate $\left(t_{\mathrm{oBU}}\right)$ and the fault is cleared $\left(\mathrm{t}_{\mathrm{cBU}}\right)$.

A diagram of the proposed protection scheme is represented in Figure 5. This scheme only represents the positive poles of each link. The protection of negative poles operates the same way as the represented protection of positive poles. This diagram is related to Bus 1 and relay R12. It illustrates how the primary protection uses the voltage measurements $\left(V_{\mathrm{L}}\right)$ taken by $\mathrm{R} 12 \mathrm{p}$, then, the voltage derivative is calculated and compared with its corresponding threshold value, and if a fault is detected inside its protection zone, a tripping signal is sent to the circuit breaker placed in link 12. Meanwhile, the backup protection employs $V_{B}$ measurements (R12b) from all neighboring links and calculates their derivatives. If a fault in the backward direction is detected and, after time $t_{\mathrm{BUdelay}}$, the circuit breaker in link 12 has not operated, tripping signals to the circuit breakers located in links 13 and 14 are issued for backup operation.

Additionally, the operation of the complete protection system proposed in this work is summarized in the flow chart shown in Figure 6. 


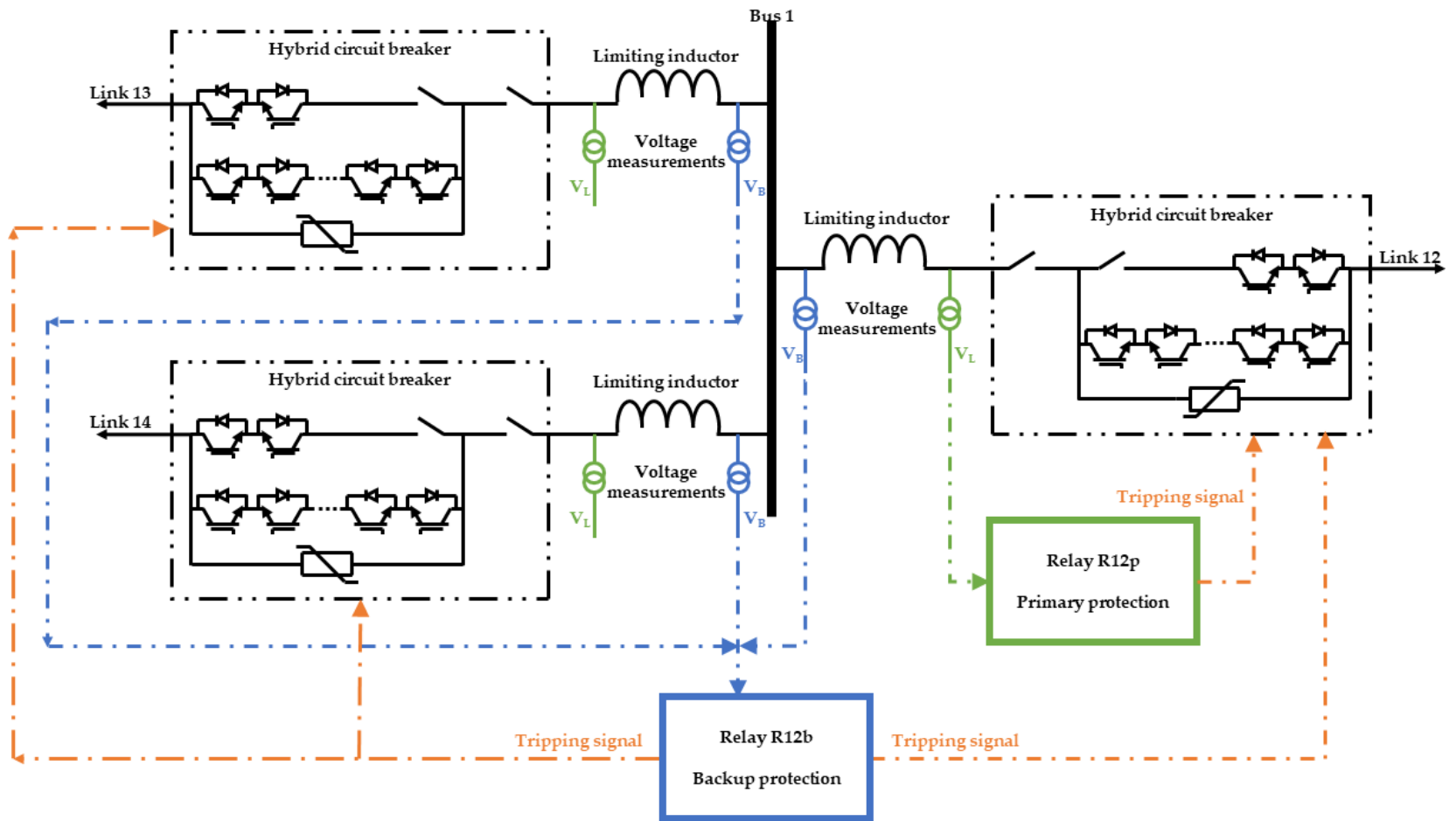

Figure 5. Diagram of the proposed protection scheme for Bus 1 and relay R12, only positive poles are represented.

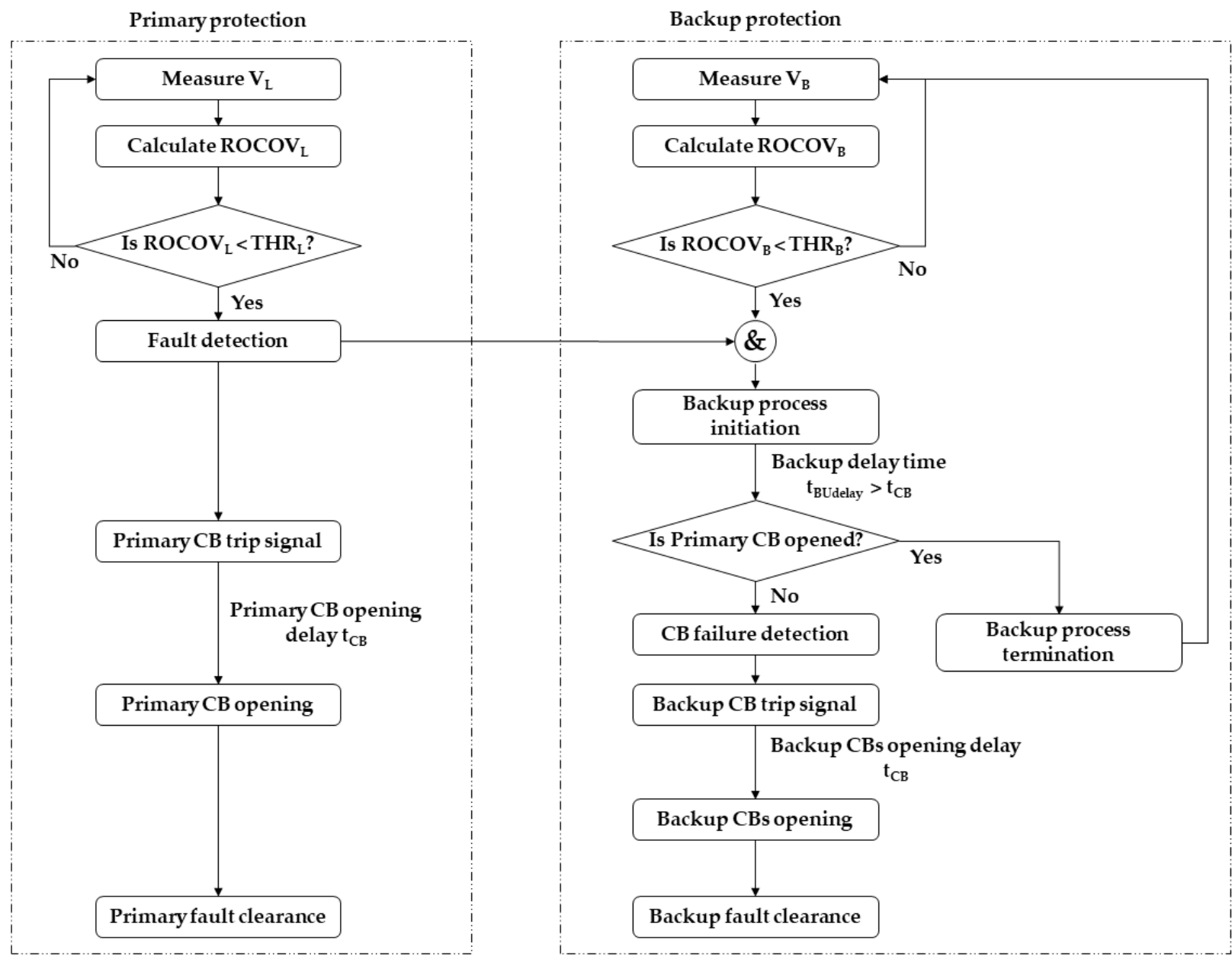

Figure 6. Flow chart of the proposed protection system. 


\section{Study Case}

The proposed protection system is applied to a four-terminal HVDC grid modeled in PSCAD software and available in [23]. The conversion topology employed is the HalfBridge Modular Multilevel Converter (HB-MMC). The rated power of HB-MMC 4 is 1200 MVA, while the rated power of the three remaining converters is 900 MVA. The HBMMCs are interconnected by five cables with $100 \mathrm{mH}$ inductors and circuit breakers at their ends; this way, each cable comprises an independent protection zone. An inductor size of $100 \mathrm{mH}$ is widely used in the literature when local-measurement-based algorithms are employed in order to accurately delimit the protection zones, e.g., [14,18-20,23-28].

Cables interconnecting converters HB-MMC 1 and 2 and HB-MMC 3 and 4 are $100 \mathrm{~km}$ long, those interconnecting HB-MMC 1 and 3 and HB-MMC 1 and 4 are $200 \mathrm{~km}$ long and the remaining one, which interconnects HB-MMC 2 and 4, is $150 \mathrm{~km}$ long. These cables are modeled by employing frequency dependent models [23].

The operation time of the circuit breakers is assumed to be $2 \mathrm{~ms}$ in accordance with the hybrid circuit breakers found in the literature [3,29]. Cable lengths are shown in Figure 7. Primary and backup protection algorithms are based on the principles stated in the preceding section. Therefore, for this HVDC system, threshold values for the primary and backup protections have been selected, i.e., $\mathrm{THR}_{\mathrm{L}}$ and $\mathrm{THR}_{\mathrm{B}}$ are $-300 \mathrm{kV} / \mathrm{ms}$ and $-5 \mathrm{kV} / \mathrm{ms}$, respectively. These threshold values have been selected by employing a safety factor for improved selectivity and to avoid noise interference, as it can be seen in Figure 3, where the threshold value depicted is $\mathrm{THR}_{\mathrm{L}}$ and there is a considerably big difference between its value and the ROCOV value during normal operation or during a close-up external fault. Moreover, a sampling frequency of $10 \mathrm{kHz}$ for ROCOV calculation and a time step of $5 \mu$ s for software simulation are employed.

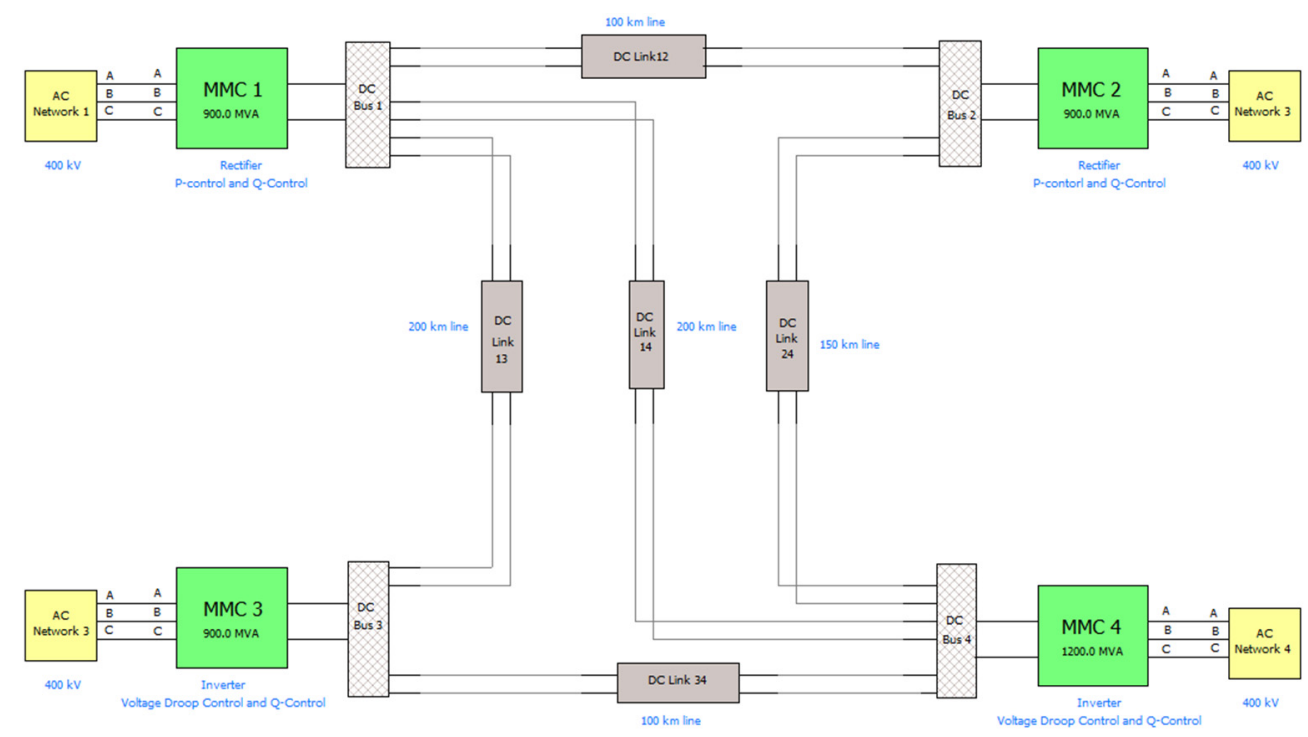

Figure 7. Model in PSCAD of the four-terminal HVDC system employed in the study case.

The proposed protection system is evaluated against different fault conditions. Hence, three fault locations are considered for each link, as shown in Figure 8. Firstly, the protection system is tested against a range of Pole-to-Pole (PtP) faults. This way, the worst fault case scenarios are analyzed. A close-up fault presents the worst fault case scenario in terms of maximum current to be dealt with. Moreover, it can be misdetected as an internal fault by primary protection of the neighboring relays. Conversely, a fault located at the other end of the protection zone is the worst fault case scenario in terms of fault detection due to the attenuation effect. Additionally, faults at the midpoint of the link are considered as well. Afterwards, the correct performance of the protection system is demonstrated against Pole-to-Ground (PtG) faults and high-resistance fault case scenarios. Additionally, it is 
verified that no nuisance operation happens when there is no circuit breaker failure due to misdetection by the backup protection.

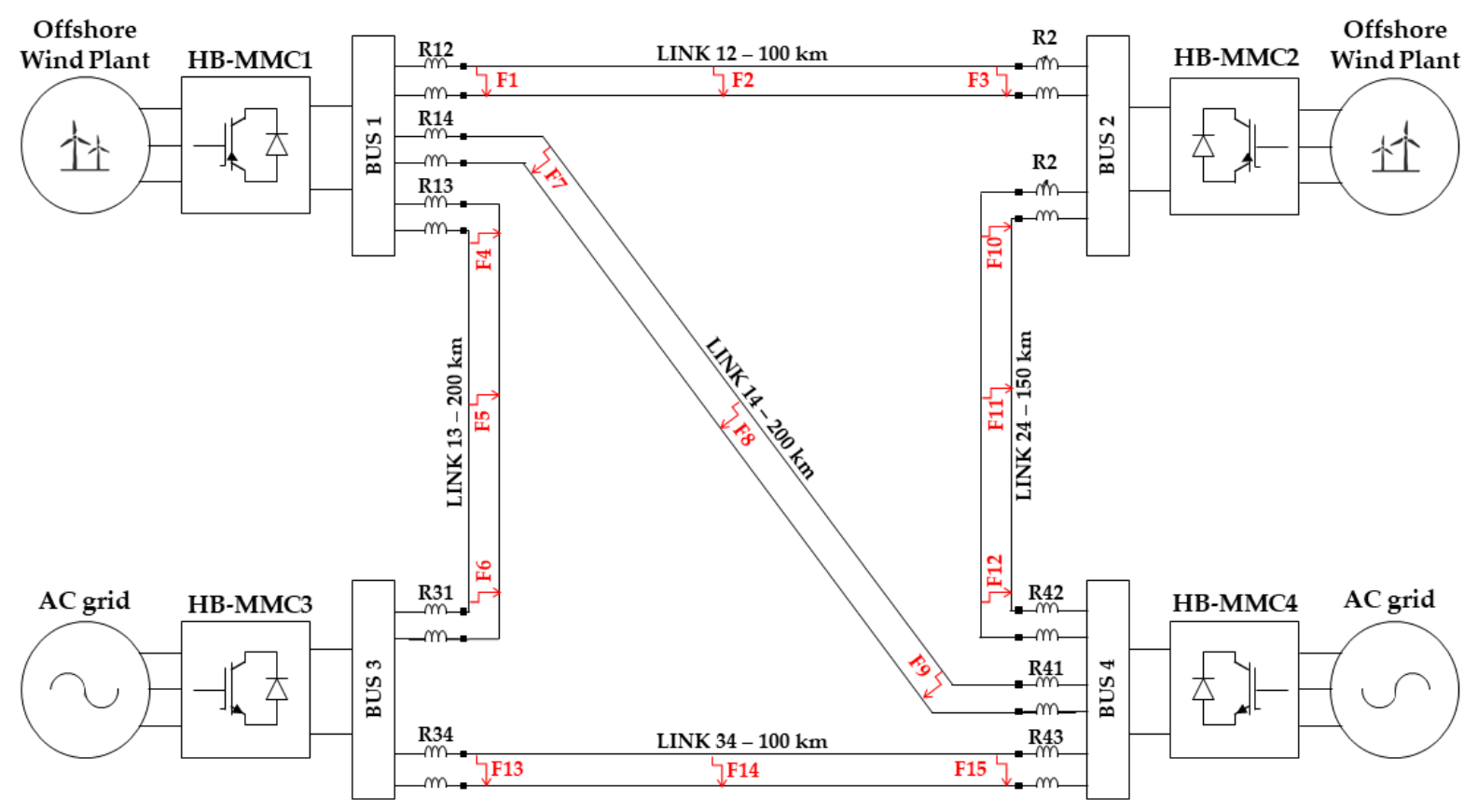

Figure 8. Diagram of the four-terminal HVDC system with locations of the simulated faults.

\subsection{Pole-to-Pole Fault Conditions}

A range of PtP faults are simulated in order to check the proper performance of the protection system. Fault locations are depicted in Figure 8. Fault F2, F5, F8, F11 and F14 are located in the middle of the respective cables, while the remaining fault cases are placed at the ends of each cable, right in front of the corresponding relays. In addition, a circuit breaker's failure condition is added to each simulated case as a way to evaluate the backup protection system. Tables 1 and 2 summarize the results of this analysis and the fault detection times (in milliseconds) related to each relay. Table 1 presents the circuit breakers that operate due to primary protection (symbol " $\mathrm{P}$ "), due to backup protection (symbol "BU") and those who should have operated as a primary protection but have not due to a malfunction (symbol " $\mathrm{F}$ "). In addition, external relays to the affected protection zone that have not misdetected the simulated fault cases are represented with symbol "-". Fault detection times regarding primary and backup protection are represented in Table 2.

Taking fault case F1 as an example, this fault should be detected by the primary protection relays R12 and R21; however, the circuit breaker corresponding to R12 presents a failure meanwhile relay R21 detects the fault at $0.555 \mathrm{~ms}$ after fault inception. Therefore, the backup protection related to the neighboring relays of R12, i.e., R13 and R14, must detect the failure in order to properly clear fault F1. As is shown in Tables 1 and 2, relays R13 and R14 are able to detect the failure of the circuit breaker related to R12 at $2.035 \mathrm{ms,}$ which is a very fast detection since the operation time of the circuit breaker is assumed to be $2 \mathrm{~ms}$. Fault clearance by R12 and R21 is achieved at 8.865 and $5.565 \mathrm{~ms}$, while the maximum current handled by the circuit breakers is 7.53 and $4.92 \mathrm{kA}$. Furthermore, no other relays detect the fault condition, which demonstrates the correct performance of the protection system. 
Table 1. Performance of the proposed protection system against different $0 \Omega \mathrm{PtP}$ fault cases.

\begin{tabular}{|c|c|c|c|c|c|c|c|c|c|c|c|}
\hline LINK & $\mathrm{F}_{\mathrm{LOC}}$ & R12 & R13 & R14 & R21 & R24 & R31 & R34 & R41 & R42 & R43 \\
\hline \multirow{3}{*}{ L12 } & $\mathrm{F} 1$ & F & BU & BU & $\mathrm{P}$ & - & - & - & - & - & - \\
\hline & F2 & $\mathrm{P}$ & - & - & $\mathrm{F}$ & BU & - & - & - & - & - \\
\hline & F3 & F & $\mathrm{BU}$ & $\mathrm{BU}$ & $\mathrm{P}$ & - & - & - & - & - & - \\
\hline \multirow{3}{*}{ L13 } & F4 & - & $P$ & - & - & - & $\mathrm{F}$ & BU & - & - & - \\
\hline & F5 & $\mathrm{BU}$ & $\mathrm{F}$ & BU & - & - & $\mathrm{P}$ & - & - & - & - \\
\hline & F6 & - & $\mathrm{P}$ & - & - & - & $\mathrm{F}$ & $\mathrm{BU}$ & - & - & - \\
\hline \multirow{3}{*}{ L14 } & F7 & $\mathrm{BU}$ & BU & F & - & - & - & - & $\mathrm{P}$ & - & - \\
\hline & F8 & - & - & $\mathrm{P}$ & - & - & - & - & F & BU & BU \\
\hline & F9 & $\mathrm{BU}$ & BU & F & - & - & - & - & $\mathrm{P}$ & - & - \\
\hline \multirow{3}{*}{ L24 } & F10 & - & - & - & $\mathrm{BU}$ & $F$ & - & - & - & $P$ & - \\
\hline & F11 & - & - & - & - & $\mathrm{P}$ & - & - & BU & $\mathrm{F}$ & BU \\
\hline & F12 & - & - & - & $\mathrm{BU}$ & $\mathrm{F}$ & - & - & - & $\mathrm{P}$ & - \\
\hline \multirow{3}{*}{ L34 } & F13 & - & - & - & - & - & - & $\mathrm{P}$ & BU & BU & $\mathrm{F}$ \\
\hline & F14 & - & - & - & - & - & BU & $\mathrm{F}$ & - & - & $\mathrm{P}$ \\
\hline & F15 & - & - & - & - & - & - & $\mathrm{P}$ & BU & BU & $\mathrm{F}$ \\
\hline
\end{tabular}

Table 2. Fault detection time in milliseconds for the proposed protection system against different $0 \Omega$ PtP fault cases.

\begin{tabular}{cccc}
\hline LINK & $\mathbf{F}_{\text {LOC }}$ & Primary Protection $\mathbf{t}_{\mathbf{d P}}(\mathbf{m s})$ & Backup Protection $\mathbf{t}_{\mathbf{d B U}}(\mathbf{m s})$ \\
\hline \multirow{2}{*}{ L12 } & $\mathrm{F} 1$ & 0.555 & 2.035 \\
& $\mathrm{~F} 2$ & 0.275 & 2.310 \\
& $\mathrm{~F} 3$ & 0.010 & 2.590 \\
\hline \multirow{2}{*}{ L13 } & F4 & 0.005 & 3.150 \\
& F5 & 0.550 & 2.590 \\
& F6 & 1.100 & 2.035 \\
\hline \multirow{2}{*}{ L14 } & F7 & 1.100 & 2.035 \\
& F8 & 0.550 & 2.595 \\
& F9 & 0.005 & 3.150 \\
\hline \multirow{2}{*}{ L24 } & F10 & 0.830 & 2.035 \\
& F11 & 0.420 & 2.450 \\
& F12 & 0.010 & 2.870 \\
\hline \multirow{2}{*}{ L34 } & F13 & 0.005 & 2.595 \\
& F14 & 0.275 & 2.310 \\
\hline
\end{tabular}

All simulated fault cases are properly detected and cleared by means of the proposed protection system.

\subsection{Pole-to-Ground Fault Conditions}

In this section, the proposed protection system is analyzed against different PtG faults. Fault locations are those depicted in Figure 8 and the results of the simulations are summarized in Tables 3 and 4 . 
Table 3. Performance of the proposed protection system against different $0 \Omega \mathrm{PtG}$ fault cases. Fault detection time in milliseconds.

\begin{tabular}{|c|c|c|c|c|c|c|c|c|c|c|c|}
\hline LINK & $\mathrm{F}_{\text {LOC }}$ & R12 & R13 & R14 & R21 & R24 & R31 & R34 & R41 & R42 & R43 \\
\hline \multirow{3}{*}{ L12 } & $\mathrm{F} 1$ & $\mathrm{P}$ & - & - & F & BU & - & - & - & - & - \\
\hline & F2 & $\mathrm{F}$ & BU & BU & $\mathrm{P}$ & - & - & - & - & - & - \\
\hline & F3 & $\mathrm{P}$ & - & - & F & BU & - & - & - & - & - \\
\hline \multirow{3}{*}{ L13 } & $\mathrm{F} 4$ & BU & F & BU & - & - & $\mathrm{P}$ & - & - & - & - \\
\hline & F5 & - & $\mathrm{P}$ & - & - & - & $\mathrm{F}$ & BU & - & - & - \\
\hline & F6 & BU & F & BU & - & - & $\mathrm{P}$ & - & - & - & - \\
\hline \multirow{3}{*}{ L14 } & F7 & - & - & $\mathrm{P}$ & - & - & - & - & $\mathrm{F}$ & BU & BU \\
\hline & F8 & $\mathrm{BU}$ & BU & F & - & - & - & - & $\mathrm{P}$ & - & - \\
\hline & F9 & - & - & $\mathrm{P}$ & - & - & - & - & $\mathrm{F}$ & $\mathrm{BU}$ & $\mathrm{BU}$ \\
\hline \multirow{3}{*}{ L24 } & F10 & - & - & - & - & $\mathrm{P}$ & - & - & BU & $\mathrm{F}$ & $\mathrm{BU}$ \\
\hline & F11 & - & - & - & BU & F & - & - & - & $\mathrm{P}$ & - \\
\hline & F12 & - & - & - & - & $\mathrm{P}$ & - & - & $\mathrm{BU}$ & $\mathrm{F}$ & $\mathrm{BU}$ \\
\hline \multirow{3}{*}{ L34 } & F13 & - & - & - & - & - & BU & F & - & - & $\mathrm{P}$ \\
\hline & F14 & - & - & - & - & - & - & $\mathrm{P}$ & BU & BU & $\mathrm{F}$ \\
\hline & F15 & - & - & - & - & - & $\mathrm{BU}$ & $\mathrm{F}$ & - & - & $\mathrm{P}$ \\
\hline
\end{tabular}

Table 4. Fault detection time in milliseconds for the proposed protection system against different $0 \Omega$ PtP fault cases.

\begin{tabular}{cccc}
\hline LINK & F $_{\text {LOC }}$ & Primary Protection $\mathbf{t}_{\mathbf{d P}}(\mathbf{m s})$ & Backup Protection $\mathbf{t}_{\mathbf{d B U}}(\mathbf{m s})$ \\
\hline \multirow{3}{*}{ L12 } & F1 & 0.005 & 2.590 \\
& F2 & 0.280 & 2.310 \\
& F3 & 0.550 & 2.035 \\
\hline \multirow{2}{*}{ L13 } & F4 & 1.100 & 2.035 \\
& F5 & 0.550 & 2.590 \\
& F6 & 0.005 & 3.150 \\
\hline \multirow{2}{*}{ L14 } & F7 & 0.005 & 3.155 \\
& F8 & 0.550 & 2.590 \\
& F9 & 1.100 & 2.035 \\
\hline \multirow{2}{*}{ L24 } & F10 & 0.010 & 2.870 \\
& F11 & 0.420 & 2.450 \\
& F12 & 0.830 & 2.030 \\
\hline \multirow{2}{*}{ L34 } & F13 & 0.550 & 2.035 \\
& F14 & 0.275 & 2.315 \\
& F15 & 0.005 & 2.590 \\
\hline
\end{tabular}

In this case, when fault F1 happens, relay R12 is able to detect it in $0.005 \mathrm{~ms}$ while a failure occurs in the circuit breaker related to relay R21. Consequently, neighboring relay R24 detects the failure and sends a tripping signal to its corresponding circuit breaker in order to clear fault F1. Failure is quickly detected by R24 at $2.590 \mathrm{~ms}$, taking into account that fault F1 is located at the other end of the protection zone. The fault clearance process ends at 4.755 and $6.110 \mathrm{~ms}$ for R12 and R21 with a maximum current interruption of 4.25 and $4.98 \mathrm{kA}$. Moreover, there is no nuisance operation by the remaining relays and all the simulated fault cases are correctly detected and cleared by the protection system.

\subsection{High-Resistance Case Scenarios}

High-resistance fault detection capability is also very relevant for the reliable operation of the system. Thus, the protection system must be tested against high-resistance faults.

First, a $200 \Omega$ PtP fault located at link L14 at $60 \mathrm{~km}$ from R14 and $140 \mathrm{~km}$ from R41 is simulated. The circuit breaker associated with R14 presents a failure in this case. After fault inception, primary protections of relays R14 and R41 detect an internal fault 
in their protection zone after 0.335 and $0.785 \mathrm{~ms}$ and tripping signals are issued to their corresponding circuit breakers. Meanwhile, the backup protection of the neighboring relays associated with R14 and R41 is initiated at 0.405 and $0.860 \mathrm{~ms}$, respectively. The corresponding circuit breaker to R41 operates at $2.790 \mathrm{~ms}$; thus, the backup protections of relays R42 and R43 are terminated. Current interruption is achieved at $3.055 \mathrm{~ms}$, while the maximum current was only $0.93 \mathrm{kA}$ due the high-resistive feature and current polarity inversion from link-bus to bus-link. Meanwhile, the circuit breaker associated with R14 presents a failure; therefore, the backup protections of relays R12 and R13 detect the circuit breaker's failure at $2.405 \mathrm{~ms}$ and issue their respective tripping signals. This way, the operation of the backup circuit breakers happens at $4.410 \mathrm{~ms}$, clearing the high-resistive fault at $5.215 \mathrm{~ms}$ (maximum current of $2.535 \mathrm{kA}$ ).

Similarly, a $200 \Omega \mathrm{PtG}$ fault is simulated. It affects link L24 and it is located at $110 \mathrm{~km}$ from R24 and $40 \mathrm{~km}$ from R42. The circuit breaker associated with the latter relay malfunctions in this simulation case. Primary protections of relays R24 and R42 detect an internal fault at 0.650 and $0.235 \mathrm{~ms}$ after fault inception and issue the tripping signals. Backup protections of the neighboring relays initiate their process at 0.710 and $0.310 \mathrm{~ms}$, respectively.

The circuit breaker related to R24 properly operates at $2.660 \mathrm{~ms}$ and the backup protection process of relay R21 is terminated. This circuit breaker has to interrupt a current of $1.51 \mathrm{kA}$ and fault clearance is achieved at $3.140 \mathrm{~ms}$ from fault inception. Conversely, the circuit breaker associated with R42 malfunctions. This operation failure is detected by relays R41 and R43 at $2.315 \mathrm{~ms}$; therefore, tripping signals are issued and circuit breakers operation is achieved at $4.320 \mathrm{~ms}$, handling a current of $0.754 \mathrm{kA}$. Thus, the high-resistance fault is properly cleared at $4.550 \mathrm{~ms}$. It must be highlighted that no remaining relay misoperates in both cases.

\subsection{Non-Failure Case Scenario}

In order to thoroughly check the performance of the backup protection, some fault cases are simulated where the primary protection clears the fault since there is no failure in its associated circuit breaker.

A solid PtP fault on link 34 located at 35 and $65 \mathrm{~km}$ from relays R34 and R43, respectively, is applied to the four-terminal grid. Fault detection is achieved at 0.195 and $0.360 \mathrm{~ms}$ by R34 and R43 after fault inception. Similarly, the backup protections of the adjacent relays initiate their processes at 0.220 and $0.395 \mathrm{~ms}$, respectively. Then, their primary circuit breakers properly operate at 2.200 and $2.370 \mathrm{~ms}$ and the backup protection identifies their correct operation and terminates their processes. Currents of 4.50 and $5.53 \mathrm{kA}$ are cleared at 5.330 and $6.425 \mathrm{~ms}$, respectively, from fault inception.

On the other hand, the performance of the backup protection against a $200 \Omega \mathrm{PtP}$ fault when there is no failure in the circuit breakers is analyzed. The high-resistance fault is located on link 12 at $80 \mathrm{~km}$ from R12 and $20 \mathrm{~km}$ from R21. In this case, the fault detection time of the primary protection is $0.445 \mathrm{~ms}$ for R12 and $0.115 \mathrm{~ms}$ for R12. Likewise, the backup protection's initiation time is 0.510 and $0.175 \mathrm{~ms}$, respectively. Therefore, circuit breakers of R12 and R21 operate at 2.450 and $2.120 \mathrm{~ms}$; thus, the backup protection's process is terminated. The maximum current handled by the circuit breakers is 1.49 and $1.83 \mathrm{kA}$. Fault clearance is achieved at 2.940 and $2.875 \mathrm{~ms}$, respectively.

No misdetection or improper operation occurred during these simulations.

\section{Discussion}

Backup protection must be able to quickly detect the failure in the clearance of a fault by an adjacent circuit breaker in order to fulfill the critical speed requirement. Moreover, a faster failure detection entails a lower maximum fault current that needs to be interrupted by the circuit breakers.

The reliable operation of the proposed backup protection has been demonstrated in Section 3 for different fault conditions, varying the fault type, location and resistance. A 
circuit breaker's failure can be quickly detected, just a few microseconds after its estimated operation time.

Figure 9 depicts the fault current waves regarding the operation of the primary and backup protection against a $0 \Omega$ PtP fault located on link L14 at $150 \mathrm{~km}$ from relay R14 and $50 \mathrm{~km}$ from R41. The current waveforms regarding normal operation and the prospective fault current are also presented. It can be seen that fault clearance related to the backup protection starts around $4 \mathrm{~ms}$ after fault detection, which supposes a $2 \mathrm{~ms}$ delay regarding the start of the primary protection's fault clearance process. This time delay of $2 \mathrm{~ms}$ is related to the time needed for a hybrid circuit breaker to commutate the fault current to the energy absorption branch, where the fault clearance process starts, after receiving the tripping signal. Figure 10 similarly shows the voltage waveform for both $\mathrm{V}_{\mathrm{L}}$ and $\mathrm{V}_{\mathrm{B}}$ for the same cases: normal operation, primary operation, backup operation and the prospective voltage related to a fault condition that has not been cleared.

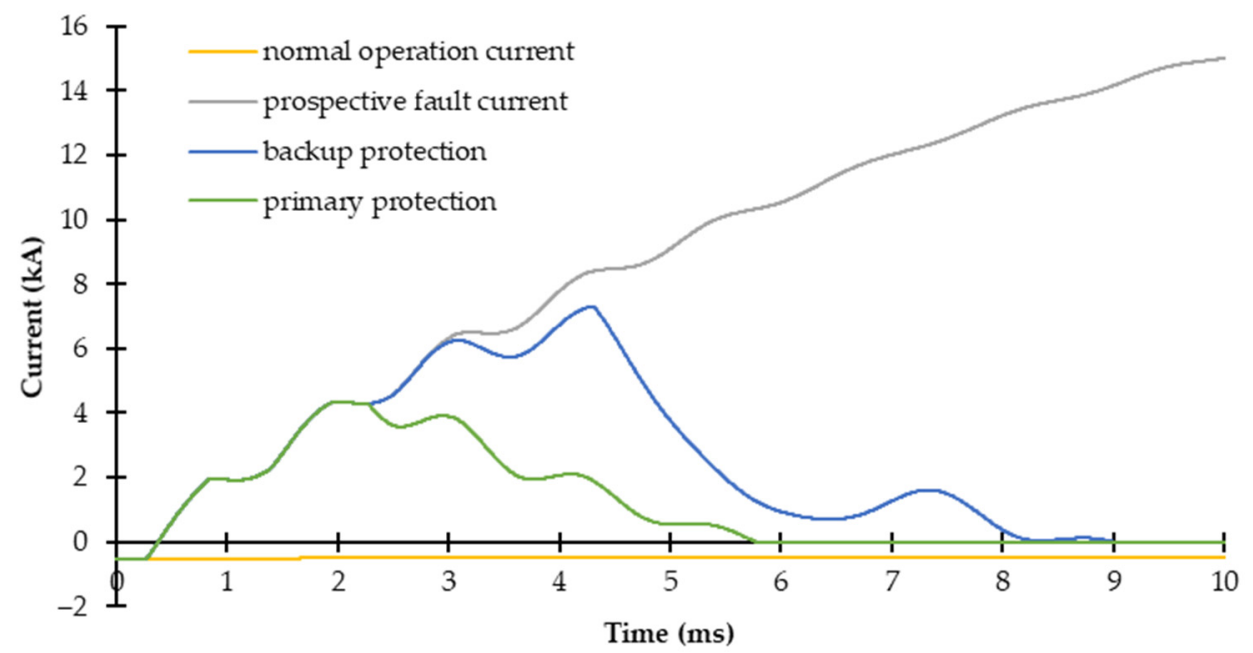

Figure 9. Comparison of fault current interruption by primary and backup protections against a $0 \Omega$ PtP fault located in line 14 at $150 \mathrm{~km}$ from R14.

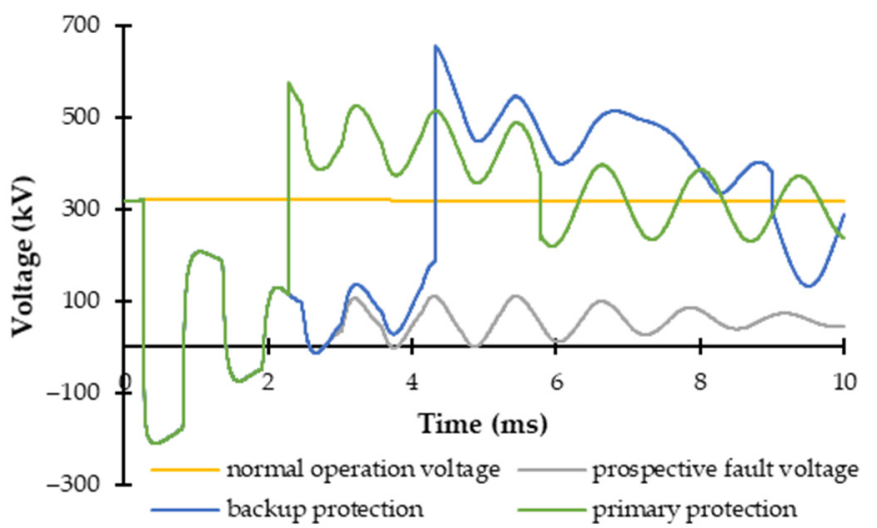

(a)

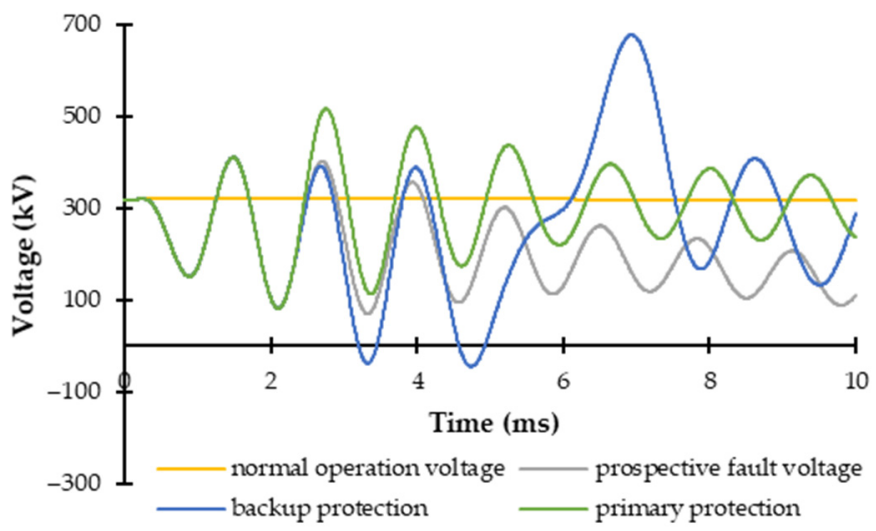

(b)

Figure 10. Comparison of (a) $\mathrm{V}_{\mathrm{L}}$ and (b) $\mathrm{V}_{\mathrm{B}}$ during primary and backup operation against a $0 \Omega$ PtP fault located in link 14 at $150 \mathrm{~km}$ from R14.

As it can be seen in Figure 9, fault clearance is achieved at approximately $6 \mathrm{~ms}$ and $8 \mathrm{~ms}$ for primary and backup protections, respectively. If a conventional backup protection had been used, failure detection would have been achieved after the estimated fault clearing time of the primary protection, i.e., approximately after $6 \mathrm{~ms}$. By this time, the fault current would have risen up to $10 \mathrm{kA}$; however, the actual fault clearing process would have started 
after an additional $2 \mathrm{~ms}$, i.e., around $8 \mathrm{~ms}$ after fault inception. By this time, the fault current would have reached very dangerous levels. However, the proposed backup protection finishes its fault clearance process at approximately $8 \mathrm{~ms}$. Thus, the proposed backup protection is faster and avoids this problematic situation related to very high fault currents.

Figure 11 shows the fault detection and the failure detection times of the primary and backup protections for a PtP fault located at link 13, varying its position from relay R13 all along the link. The detection times are proportional to the fault location and the delay between them is slightly higher than $2 \mathrm{~ms}$ (the assumed operation time of a hybrid circuit breaker). Moreover, solid (solid line) and $200 \Omega$ (discontinued line) fault cases are simulated and it is concluded that the effect of the fault resistance on the backup protection can be neglected.

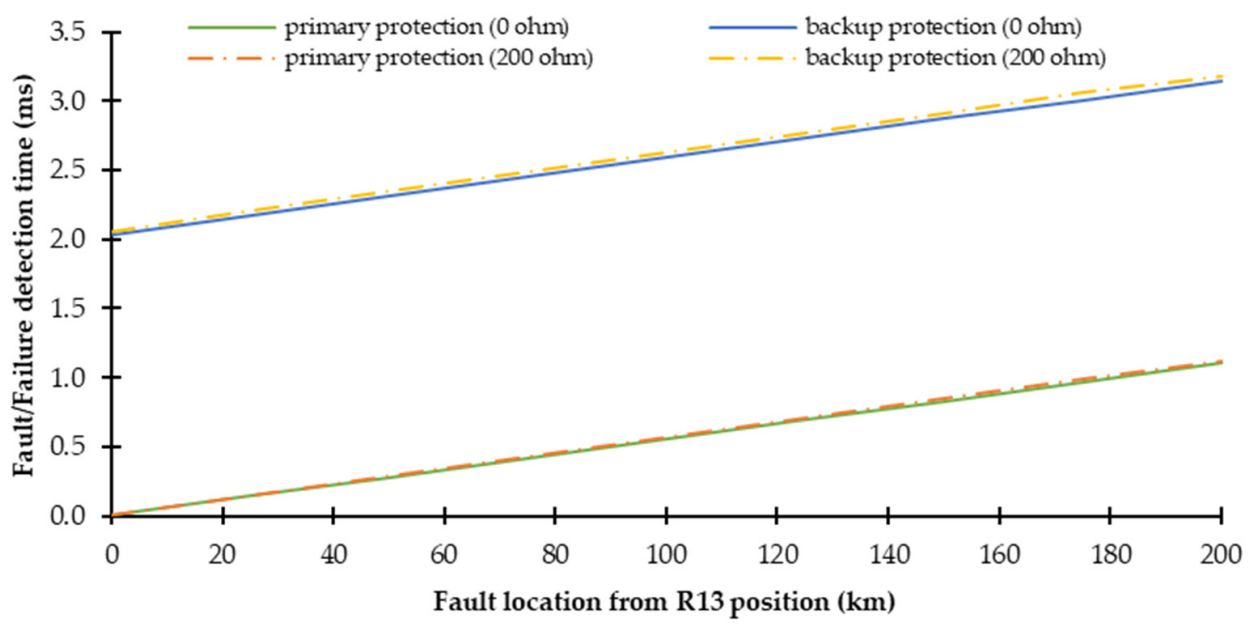

Figure 11. Fault detection time of primary and backup protections against solid (solid line) and 200 $\Omega$ (discontinued line) faults varying the fault location.

Additionally, Figure 12 presents the maximum fault currents dealt by the affected circuit breakers for the previously mentioned fault cases. The maximum fault current is higher when the backup protection operates due to the 2 ms delay, i.e., primary operation of the circuit breakers happens around $2 \mathrm{~ms}$ after fault inception, while backup operation takes place after $4 \mathrm{~ms}$. The maximum fault current difference is in the range of less than $1 \mathrm{kA}$ and $2 \mathrm{kA}$. The primary protection deals with a maximum of $6 \mathrm{kA}$, while the backup protection has to interrupt up to $8 \mathrm{kA}$.

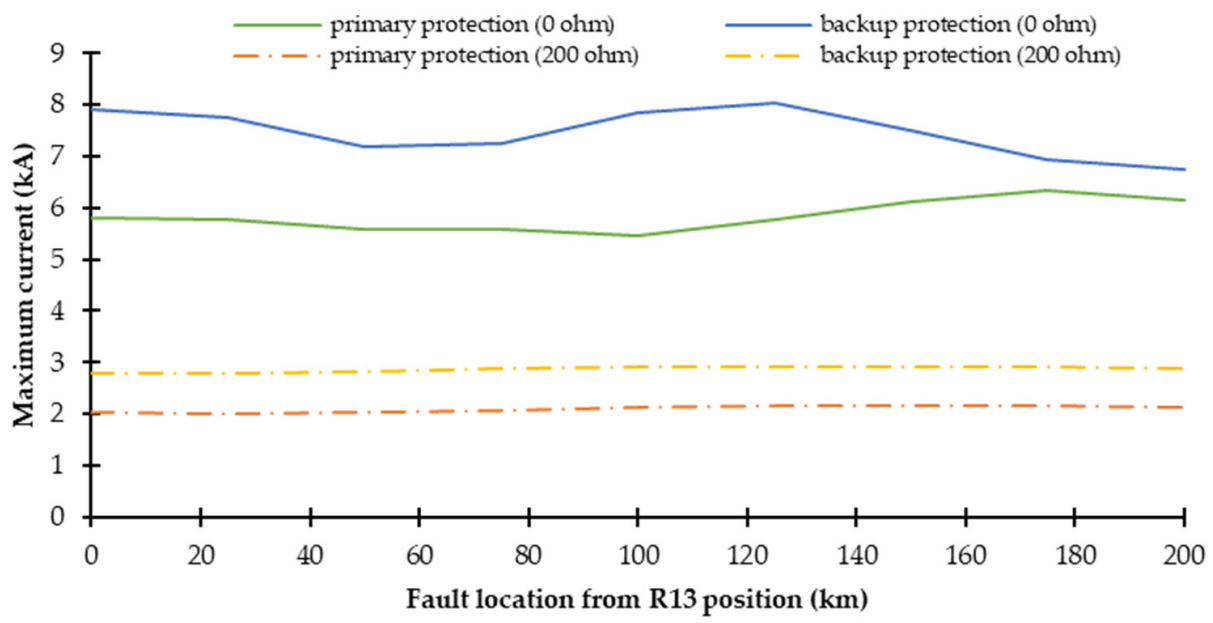

Figure 12. Maximum current handled by the CBs during operation of primary and backup protections against solid (solid line) and $200 \Omega$ (discontinued line) faults varying the fault location. 


\section{Conclusions}

There is a need for the identification of the potential failure modes of the operating HVDC circuit breakers, considering that the failure of a circuit breaker implies severe consequences for the HVDC grid. In this paper, a novel protection strategy that deals with the failure to trip of HVDC circuit breakers is presented. This novel backup strategy assists the malfunctioning of the primary protection, activating the neighboring circuit breakers. In consequence, the zone of backup protection overlaps each adjacent system element. It is able to detect the failure faster than the conventional backup protections, which have to wait after the estimated fault clearing time. This way, the fault current does not increase up to dangerous levels for the VSC-based system.

The proposed strategy is based on ROCOV algorithms for primary and backup protections, which are calculated at both ends of the limiting inductors that delimit each primary protection zone. Therefore, in case a circuit breaker fails to trip when requested, the adjacent circuit breakers operate as a way to clear the fault. Naturally, when the backup protection operates a larger part of the system is disconnected, compared with the primary protection appropriate operation.

The proposed strategy can be used with distinct primary protection algorithms and grid configurations. In the paper, it is validated in a four-terminal HVDC grid, considering three fault locations in each link. Close-up, remote and midlink locations are evaluated for $\mathrm{PtP}, \mathrm{PtG}$ and high-resistance faults. All the considered case studies are properly detected and cleared without any nuisance operation. Additionally, it has been verified that when primary protections clear the faults, the backup protection process is interrupted. Therefore, it can be concluded that the proposed protection strategy is reliable, robust and remarkably fast.

Author Contributions: Conceptualization, methodology, and writing—review and editing: M.J.P.-M., D.M.L., P.E. and O.A.; Supervision: D.M.L., P.E. and O.A.; Funding acquisition: P.E., D.M.L. and M.J.P.-M.; Writing—original draft preparation: M.J.P.-M. and D.M.L.; and Software, validation, formal analysis, investigation, data curation, visualization, and project administration: M.J.P.-M. All authors have read and agreed to the published version of the manuscript.

Funding: This research was funded by the Basque Government (GISEL research group IT1191-19) and the University of the Basque Country UPV/EHU (GISEL research group 181/18 and PIF20/06).

Conflicts of Interest: The authors declare no conflict of interest. The funders had no role in the design of the study; in the collection, analyses, or interpretation of data; in the writing of the manuscript, or in the decision to publish the results.

\section{References}

1. CIGRÉ WG B4.52. HVDC Grid Feasibility Study. Cigré 2013.

2. Perez-Molina, M.J.; Larruskain, D.M.; Eguia Lopez, P.; Buigues, G.; Valverde, V. Review of protection systems for multi-terminal high voltage direct current grids. Renew. Sustain. Energy Rev. 2021, 144, 111037. [CrossRef]

3. Franck, C.M. HVDC Circuit Breakers: A Review Identifying Future Research Needs. IEEE Trans. Power Deliv. 2011, 26, 998-1007. [CrossRef]

4. Haleem, N.M.; Rajapakse, A.D.; Gole, A.M.; Fernando, I.T. A Selective Fault Clearing Scheme for a Hybrid VSC-LCC MultiTerminal HVdc System. Energies 2020, 13, 3554. [CrossRef]

5. Mohammadi, F.; Rouzbehi, K.; Hajian, M.; Niayesh, K.; Gharehpetian, G.B.; Saad, H.; Ali, M.H.; Sood, V.K. HVDC Circuit Breakers: A Comprehensive Review. IEEE Trans. Power Electron. 2021, 1. [CrossRef]

6. Zhou, J.; Li, H.; Xie, R.; Liu, L.; Nie, W.; Song, K.; Huo, F.; Liang, D. Research of DC circuit breaker applied on zhoushan multi-terminal VSC-HVDC project. In Proceedings of the IEEE PES Asia-Pacific Power and Energy Engineering Conference (APPEEC), Xi'an, China, 25-28 October 2016; pp. 1636-1640.

7. Belda, N.A.; Smeets, R.P.P.; Nijman, R.M. Experimental Investigation of Electrical Stresses on the Main Components of HVDC Circuit Breakers. IEEE Trans. Power Deliv. 2020, 35, 2762-2771. [CrossRef]

8. Yousaf, M.Z.; Liu, H.; Raza, A.; Baig, M.B. Primary and backup fault detection techniques for multi-terminal HVdc systems: A review. IET Gener. Transm. Distrib. 2020, 14, 5261-5276. [CrossRef]

9. Leterme, W.; Azad, S.P.; Van Hertem, D. Fast breaker failure backup protection for HVDC grids. In Proceedings of the Conference on Power Systems Transients (IPST2015), Cavtat, Croatia, 15-18 June 2015. 
10. Wang, M.; Leterme, W.; Beerten, J.; Van Hertem, D. Robustness evaluation of fast breaker failure backup protection in bipolar HVDC grids. In Proceedings of the 13th IET International Conference on AC and DC Power Transmission (ACDC 2017), Manchester, UK, 14-16 February 2017.

11. Azad, S.P.; Leterme, W.; Van Hertem, D. Fast Breaker Failure Backup Protection for HVDC Grids. Electr. Power Syst. Res. 2016, 138, 99-105. [CrossRef]

12. Leterme, W.; Azad, S.P.; Van Hertem, D. A Local Backup Protection Algorithm for HVDC Grids. IEEE Trans. Power Deliv. 2016, 31, 1767-1775. [CrossRef]

13. Yu, J.; Zhang, Z.; Xu, Z. A Local Protection and Local Action Strategy of DC Grid Fault Protection. Energies 2020, 13 , 4795. [CrossRef]

14. Pérez-Molina, M.J.; Larruskain, D.M.; Eguia López, P.; Etxegarai, A. Analysis of Local Measurement-Based Algorithms for Fault Detection in a Multi-Terminal HVDC Grid. Energies 2019, 12, 4808. [CrossRef]

15. Dao, V.Q.; Lee, J.; Kim, C.S.; Park, M.; Melaccio, U. Design and Performance Analysis of a Saturated Iron-Core Superconducting Fault Current Limiter for DC Power Systems. Energies 2020, 13, 6090. [CrossRef]

16. Haleem, N.M.; Rajapakse, A.D. Application of new directional logic to improve DC side fault discrimination for high resistance faults in HVDC grids. J. Mod. Power Syst. Clean Energy 2017, 5, 560-573. [CrossRef]

17. Haleem, N.M.; Rajapakse, A.D. Local measurement based ultra-fast directional ROCOV scheme for protecting Bi-pole HVDC grids with a metallic return conductor. Int. J. Electr. Power Energy Syst. 2018, 98, 323-330. [CrossRef]

18. Sneath, J.; Rajapakse, A.D. DC fault protection of a nine-terminal MMC HVDC grid. In Proceedings of the 11th IET International Conference on AC and DC Power Transmission, Birmingham, UK, 10-12 February 2015; pp. 1-8.

19. Sneath, J.; Rajapakse, A.D. Fault Detection and Interruption in an Earthed HVDC Grid Using ROCOV and Hybrid DC Breakers. IEEE Trans. Power Deliv. 2016, 31, 973-981. [CrossRef]

20. Pérez-Molina, M.J.; Eguia, P.; Larruskain, D.M.; Buigues, G.; Torres, E. Non-unit ROCOV scheme for protection of multi-terminal HVDC systems. In Proceedings of the 22nd European Conference on Power Electronics and Applications (EPE ECCE Europe 2020), Lyon, France, 7-11 September 2020.

21. Pérez-Molina, M.J.; Larruskain Escobal, D.M.; Eguia Lopez, P.; Valverde Santiago, V. Fault detection based on ROCOV and ROCOC for multi-terminal HVDC systems. In Proceedings of the 20th IEEE Mediterranean Electrotechnical Conference (MELECON 2020), Palermo, Italy, 16-18 June 2020; pp. 506-511.

22. Zhang, C.; Song, G.; Wang, T.; Dong, X. An Improved Non-Unit Traveling Wave Protection Method With Adaptive Threshold Value and Its Application in HVDC Grids. IEEE Trans. Power Deliv. 2020, 35, 1800-1811. [CrossRef]

23. Leterme, W.; Ahmed, N.; Beerten, J.; Ängquist, L.; Hertem, D.V.; Norrga, S. A new HVDC grid test system for HVDC grid dynamics and protection studies in EMT-type software. In Proceedings of the 11th IET International Conference on AC and DC Power Transmission, Birmingham, UK, 10-12 February 2015.

24. Rahman, H.; Xu, L.; Bell, K. DC fault protection of multi-terminal HVDC systems using DC network partition and DC circuit breakers. In Proceedings of the Protection, Automation and Control World Conference (PAC World 2015), Glasgow, UK, 29 June-2 July 2015.

25. Mokhberdoran, A.; Silva, N.; Leite, H.; Carvalho, A. Unidirectional Protection Strategy for Multi-terminal HVDC Grids. Trans. Environ. Electr. Eng. 2016, 1, 58. [CrossRef]

26. Yeap, Y.M.; Geddada, N.; Satpathi, K.; Ukil, A. Time-and Frequency-Domain Fault Detection in a VSC-Interfaced Experimental DC Test System. IEEE Trans. Ind. Inform. 2018, 14, 4353-4364. [CrossRef]

27. Li, Y.; Wu, L.; Li, J.; Xiong, L.; Zhang, X.; Song, G.; Xu, Z. DC Fault Detection in MTDC Systems Based on Transient High Frequency of Current. IEEE Trans. Power Deliv. 2019, 34, 950-962. [CrossRef]

28. Pérez-Molina, M.J.; Larruskain, D.M.; Eguia Lopez, P.; Abarrategi, O.; Santos-Mugica, M. A comparison of non-unit and unit protection algorithms for HVDC grids. In Proceedings of the AEIT HVDC International Conference 2019, Florence, Italy, 9-10 May 2019.

29. Häfner, J.; Jacobson, B. Proactive hybrid HVDC breakers-A key innovation for reliable HVDC grids. In Proceedings of the Electric Power System of the Future-Integrating Supergrids and Microgrids International Symposium, Bologna, Italy, 13-15 September 2011. 